\title{
Paper
}

\section{The Behaviour of Low Alloy Steel Powder during Uniaxial Cold Compaction - Influence of the Geometry}

\author{
Ilaria CRISTOFOLINI ${ }^{1}$, Alberto MOLINARI ${ }^{1}$, Gianluca PEDERZINI ${ }^{2}$ and Alex RAMBELLI ${ }^{2}$ \\ ${ }^{1}$ Department of Industrial Engineering, University of Trento, Via Sommarive 9, 38123 Trento, Italy. \\ ${ }^{2}$ Powder Metal B.U., Sacmi Imola S.C., Via Provinciale Selice 17, 40026 Imola (BO), Italy.
}

Received December 1, 2017; Revised January 25, 2018; Accepted January 31, 2018

\begin{abstract}
This work investigates the influence of geometry on the behaviour of a commercial diffusion bonded low alloy steel powder (added by $0.65 \%$ graphite and $0.6 \%$ lubricant) during uniaxial cold compaction. Cylindrical specimens and ring-shaped specimens were produced, characterized by different geometrical parameters. The whole analysis has been performed using experimental data, the forces and displacements continuously recorded by an industrial press without any additional device, aiming at obtaining results representing the actual conditions in the production of real parts. The stress field acting on the powder column was derived from the recorded data, obtained from two different compaction strategies. By single action cold compaction experiments the parameters characteristics of the powder mix were derived, such as the radial stress transmission coefficient, the flow stress, the friction coefficient with the die walls, and the friction coefficient with the core in case of rings. These results were used investigating the powder behaviour during double action cold compaction, which represents the most common compaction strategy. Densification curves were derived from this analysis, reporting the relative density as a function of both the applied and the mean axial stress. The influence of the geometry on the densification was highlighted and discussed.
\end{abstract}

\section{KEY WORDS}

Uniaxial cold compaction, constitutive model, low alloy steel powder

\section{Introduction}

The behaviour of powders during uniaxial cold compaction has been extensively studied, and several equations have been proposed, defining the relationship applied pressure/porosity ${ }^{1-4)}$ or the relationship applied pressure/relative density ${ }^{5-8)}$. The different aspects affecting densification have been considered from time to time, as chemical composition of the powder mix, particle size, morphology and distribution ${ }^{9-11)}$, friction with die walls and interparticle friction ${ }^{12,13)}$, tri-axial state of stress ${ }^{14}$.

This work has been developed within a large project aimed at investigating the behaviour of the powder mix during uniaxial cold compaction, using the data continuously recorded by an industrial press without any additional special device. The methodology developed in previous work has allowed obtaining the constitutive model of different powder mixes by means of the forces and displacements recorded by the press, using different compaction strategies ${ }^{15-17)}$. Moreover, a densification equation based on the deformation of the powder column, with actual physical meaning, has been proposed ${ }^{18)}$. In this way, the relationships describing powder behaviour during uniaxial cold compaction are strictly

* Corresponding author, E-mail: ilaria.cristofolini@unitn.it related to the whole of phenomena actually determining densification during compaction.

Aiming at enlarging the field of application, the influence of geometry has been investigated in this work. Disks and rings characterized by different height have been studied, starting from consideration that most of the axi-symmetric real parts can be considered as combination of coaxial disks and rings. The influence of geometry on relative in situ density, as a function of both applied stress and mean axial stress, has been determined. The axial gradient of density, which is crucial information in designing the compaction strategy, has been determined for all the parts studied.

\section{Experimental procedure}

A commercial diffusion bonded low alloyed steel powder $2 \% \mathrm{Cu}, 1.5 \% \mathrm{Mo}$ - added by $0.65 \%$ graphite and $0.6 \%$ Kenolube as lubricant, was compacted using a 200 tonnes hydraulic press, equipped with 9 hydraulic and 1 electric closed-loop controlled axes.

Aiming at investigating the influence of geometry on the behaviour of powder mix during compaction, both cylindrical and ring shaped specimens have been produced. Cylindrical specimens were compacted in a rigid die $35 \mathrm{~mm}$ diameter (D), and ring shaped specimens were compacted up in a rigid die $35 \mathrm{~mm}$ diameter 
$\left(D_{\text {ext }}\right)$, core $15 \mathrm{~mm}$ diameter $\left(D_{\text {int }}\right)$. Specimens were classified according to the geometrical parameters H/D ratio for disks, and $\mathrm{H} /\left(\mathrm{D}_{\text {ext }}-\mathrm{D}_{\text {int }}\right)$ ratio for rings, both being in strict relationship with the geometrical parameters in the equation describing the gradient of force ${ }^{19)}$. Two different H/D ratios, 0.8 and 1.3 (28 and $45.5 \mathrm{~mm}$ height, respectively) were considered for disks, and three different $\mathrm{H} /\left(\mathrm{D}_{\text {ext }}-\mathrm{D}_{\text {int }}\right)$ ratios, $1,1.5$, and $2(20,30$, and $40 \mathrm{~mm}$ height, respectively) for rings. Both disks and rings were compacted up to $7.1 \mathrm{~g} / \mathrm{cm}^{3}$ green density. Different compaction strategies were used: "double action" pressing (obtained by moving the die downwards at half the speed as the upper punch), and "single action" pressing (obtained with stationary die). This latter compaction strategy was mainly aimed at deriving the mechanics relationships from the recorded data, as described in previous work ${ }^{20)}$.

The following parameters were continuously recorded during compaction:

- F, compaction force, the force applied to the crosshead (related to the force applied to the powder column by the upper punch);

$-F_{d}$, the force applied to the die (aimed at controlling the movement of the die according to the different compaction strategies);

- X, the position of the lower surface of the upper punch with respect to the upper surface of the lower punch (as derived from the distance measured by one encoder consisting of two parts, one fixed to the crosshead and one fixed to the base plate of the press, respectively);

- Z, the position of the upper surface of the die, again with respect to the upper surface of the lower punch (as derived from the distance measured by one encoder consisting of two parts, one fixed to the die plate and one fixed to the base plate of the press, respectively);

In the case of rings, the parameters related to the core were also recorded, that is:

- $F_{c}$, the force applied to the core (aimed at controlling the movement of the core according to the different compaction strategies);

$-Z_{1}$, the position of the upper surface of the core, again with respect to the upper surface of the lower punch (as derived from the distance measured by one encoder consisting of two parts, one fixed to the core plate and one fixed to the base plate of the press, respectively).

Fig. 1 shows an example of the curves of upper punch (X) and die $(\mathrm{Z})$ positions versus time, together with the curves of the compaction force $(F)$ and the force applied to the die $\left(F_{d}\right)$ for the cylindrical specimens $(H / D=1.3)$, together with an example of the curves of upper punch $(X)$, die $(Z)$, and core $\left(Z_{1}\right)$ positions versus time, and the curves of the compaction force $(F)$, the force applied to the die $\left(\mathrm{F}_{\mathrm{d}}\right)$, and the force applied to the core $\left(\mathrm{F}_{\mathrm{c}}\right)$ for the ring shaped specimens $\left(H / /\left(D_{\text {ext }}-D_{\text {int }}\right)=2\right)$, double action cold compaction strategy.

\section{Results and discussion}

From the recorded data, relative in situ density $\rho$ and compaction pressure $\sigma_{a u}$ can be directly obtained, as by equations (1) and (2)

Disks $\rho_{r}=\rho / \rho_{t h}=\left(4 m / \pi h D^{2}\right) \cdot 1 / \rho_{t h}$ Rings $\rho_{r}=\rho / \rho_{t h}=\left[4 m / \pi h\left(D_{e x t}{ }^{2}-D_{\text {int }}{ }^{2}\right)\right] \cdot 1 / \rho_{\text {th }}(1)$ Disks $\sigma_{a u}=4 F / \pi D^{2} \quad$ Rings $\sigma_{a u}=4 F / \pi\left(D_{\text {ext }}{ }^{2}-D_{\text {int }}{ }^{2}\right)$

Where $m$ is the mass of the powder, $h$ is the height in situ of the powder column (to which the elastic displacement of the tooling has been added $\left.{ }^{15}\right)$ and $\rho_{\text {th }}$ is the theoretical density of the powder mix, also comprehending lubricant and graphite $\left(\rho_{t h}=7.5 \mathrm{~g} / \mathrm{cm}^{3}\right)$. Fig. 2 shows relative in situ density as a function of the compaction stress for all the geometries.

As expected, a higher compaction stress is needed to obtain the same relative in situ density on increasing $H / D$, and $H /\left(D_{\text {ext }}-D_{\text {int }}\right)$, due to the different gradient of force. This is mainly evident when observing the enlarged frames in Fig. $2 a$ and $2 b$, while in the first compaction stage curves are almost overlapped. Moreover, differences between disks and rings can be highlighted, and in this case they are mainly in the first compaction stage, as it will be analysed in depth in the following. Nevertheless, it must be observed that relative in situ density and compaction stress are not strictly coherent entities: the first is the mean relative in situ density within the powder column, while the latter is the stress corresponding to the particles in the powder column close to the upper punch. Moving to mean axial stress $\sigma_{a}$, in double action compaction the force exerted by the lower punch is about the same 1a)
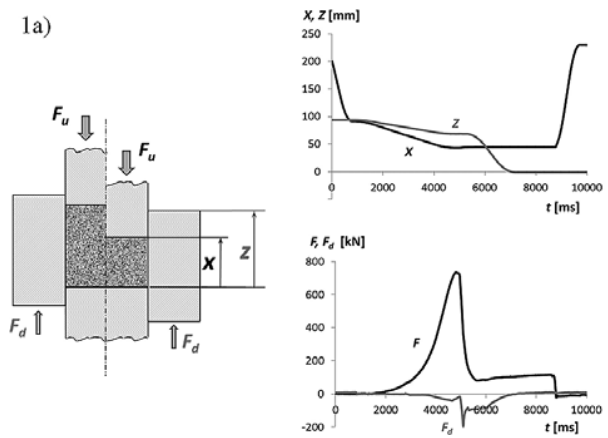

1b)
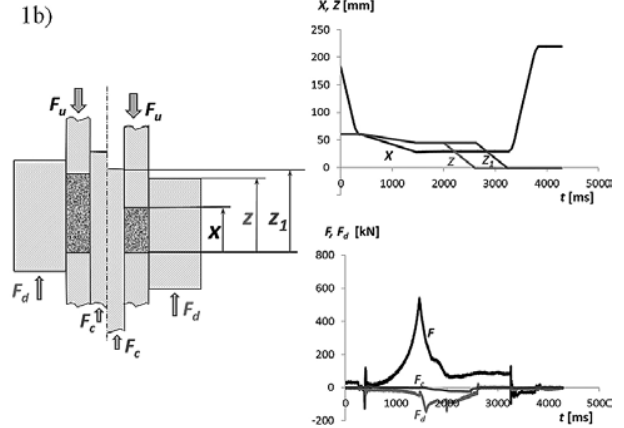

Fig. 1 Parameters continuously recorded by the press - double action compaction of disks (1a) and rings (1b). 
2a)

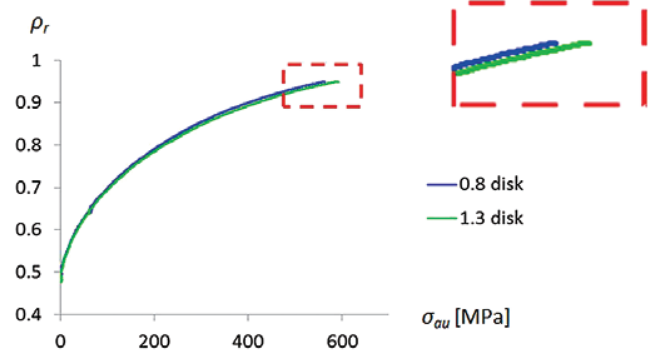

2b)
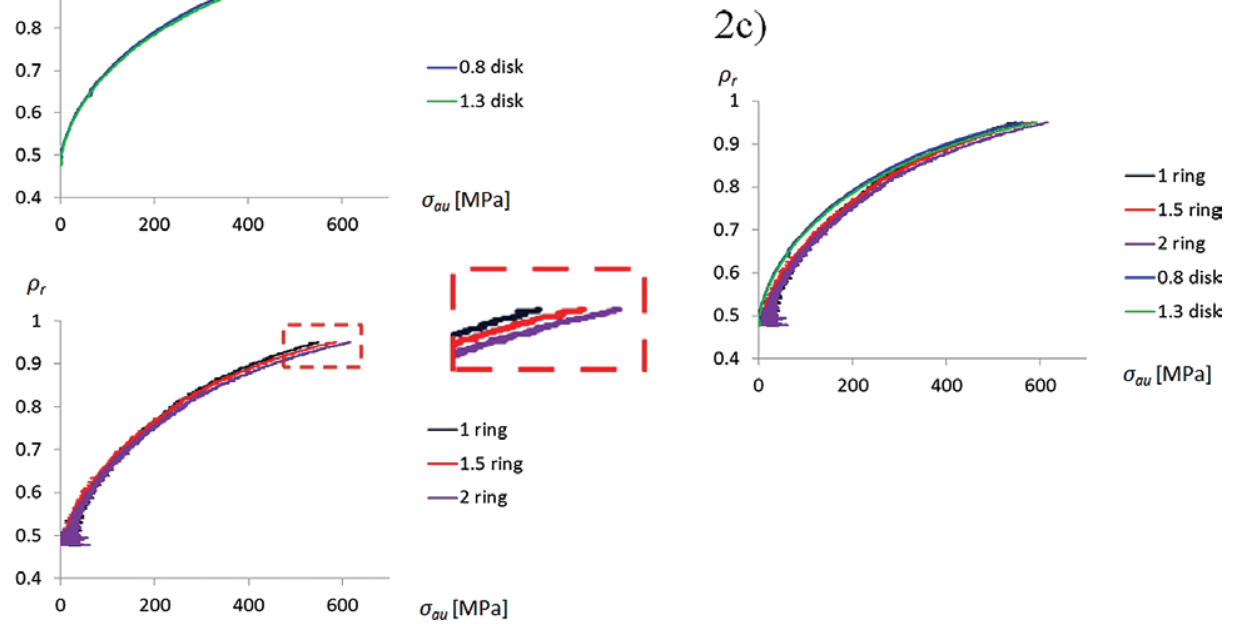

Fig. 2 Relative in situ density versus compaction stress - disks (2a), rings (2b), disks and rings (2c).

Table 1 Friction coefficients and radial stress transmission coefficient derived from single action experiments.

\begin{tabular}{llrrrrr}
\hline & $\mathrm{H} / \mathrm{D}$ & $\mathrm{H} /\left(\left(\mathrm{D}_{\text {ext }}-\mathrm{D}_{\text {int }}\right)\right.$ & $\mu$ & $\mu_{\text {ext }}$ & $\mu_{\text {int }}$ & $K=\sigma_{r} / \sigma_{a}$ \\
\hline \multirow{3}{*}{ Disks } & 0.4 & & 0.21 & & & \\
& 0.7 & & 0.20 & & \\
\multirow{3}{*}{ Rings } & & 0.5 & 0.20 & 0.19 & $K_{e l}=0.008 \rho_{r}-0.31$ \\
& & 0.75 & 0.19 & 0.17 & $K_{p l}=0.84 \rho_{r}-0.35$ \\
& 1 & & 0.18 & 0.15 & \\
\hline
\end{tabular}

as the compaction force, and the minimum axial force is expected to correspond to mid-height. The gradient of force from the top to mid- height reasonably follows a linear trend in presence of lubricant (same, symmetrically, from the bottom to mid-height), so that the mean axial stress can be obtained by equations (3)

Disks $\sigma_{a}=\left[\left(F+F_{H / 2}\right) / 2\right] \cdot 4 / \pi D^{2}$ Rings $\sigma_{a}=\left[\left(F+F_{H / 2}\right) / 2\right] \cdot 4 / \pi\left(D_{\text {ext }}{ }^{2}-D_{\text {int }}{ }^{2}\right)$

Where $\mathrm{F}_{\mathrm{H} / 2}$ is the force at mid-height, which is given by equations (4)

Disks $F_{H / 2}=F \cdot \exp \left[\left(-4 \sigma_{r} / \sigma_{a}\right) \cdot(\mu H / 2 D)\right]$

Rings $F_{H / 2}=F \cdot \exp \left[\left(-4 \sigma_{r} / \sigma_{a}\right) \cdot\left(\mu_{\text {ext }} D_{\text {ext }}+\mu_{i n t} D_{\text {int }} / D_{\text {ext }}{ }^{2}-D_{\text {int }}{ }^{2}\right) \cdot(H / 2)\right]$

Missing parameters in determining $F_{H / 2}$, and in turn mean axial stress, are the friction coefficients with die walls ( $\mu$ for disks and $\mu_{\text {ext }}$ for rings) and, for rings, with core $\left(\mu_{i n t}\right)$, as well as the radial stress transmission coefficient $K=\sigma_{r} / \sigma_{a}$. The above parameters can be obtained by single action cold compaction experiments, as explained in depth in previous work ${ }^{16)}$. Aiming at obtaining the same gradient of force, single action experiments have been performed on half the height specimens, that means disks $\mathrm{H} / \mathrm{D}=0.4$, 0.7 and rings $H /\left(D_{\text {ext }}-D_{\text {int }}\right)=0.5,0.75,1$. Results obtained from single action experiments are summarized in Table 1.
By the results of single action experiments the mean axial stress is derived, and relative in situ density is shown in Fig. 3 as a function of mean axial stress

Overlapping among curves of disks and rings in the last compaction stage significantly improved, as by the enlarged frames in Fig. 3a and $3 \mathrm{~b}$; nevertheless differences still remain at the beginning of compaction when comparing disks and rings, as shown by framed area in Fig. 3c. This result leads to investigate any effect of starting density. In situ starting density $\rho_{0}$ is directly related to the height of powder column at the beginning of compaction by equation (5).

Disks $\rho_{0}=\left(4 m / \pi h_{0} D^{2}\right) \quad$ Rings $\rho_{0}=\left[4 m / \pi h_{0}\left(D_{\text {ext }}{ }^{2}-D_{\text {int }}{ }^{2}\right)\right]$

With respect to starting density, densification is given by the increase in density during compaction, which is determined by the deformation of the powder column. Under the reasonable hypothesis of infinitely rigid die and core, the deformation of the powder column is given by the dimensional change of height, and consequently densification is described in terms of deformation by equation $(6)^{18)}$. Relationship is derived for disks expressing height by means of equation (5), but it is exactly the same for rings.

$\varepsilon=\left(h_{0}-h\right) / h_{0}=1-h / h_{0}=1-\left(4 m / \pi \rho D^{2}\right) /\left(4 m / \pi \rho_{0} D^{2}\right)=1-\rho_{0} / \rho$ 
3a)

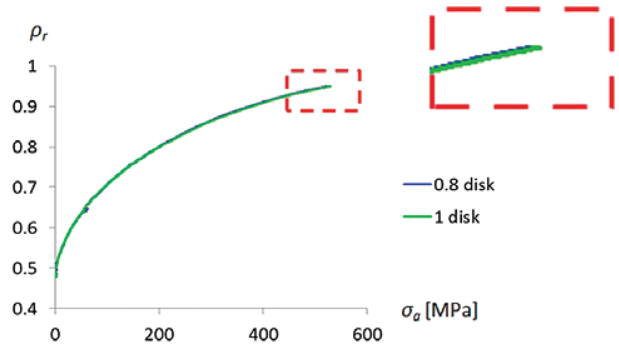

3b)

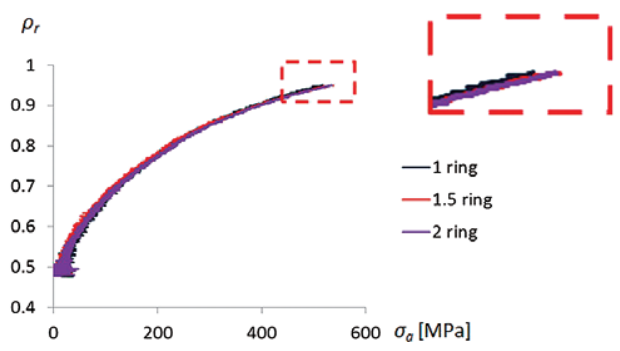

$3 \mathrm{c})$

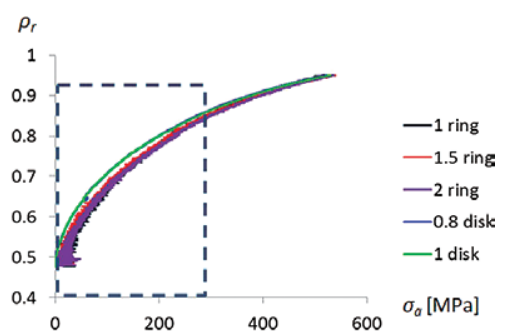

Fig. 3 Relative in situ density versus mean axial stress - disks (3a), rings (3b), disks and rings (3c).
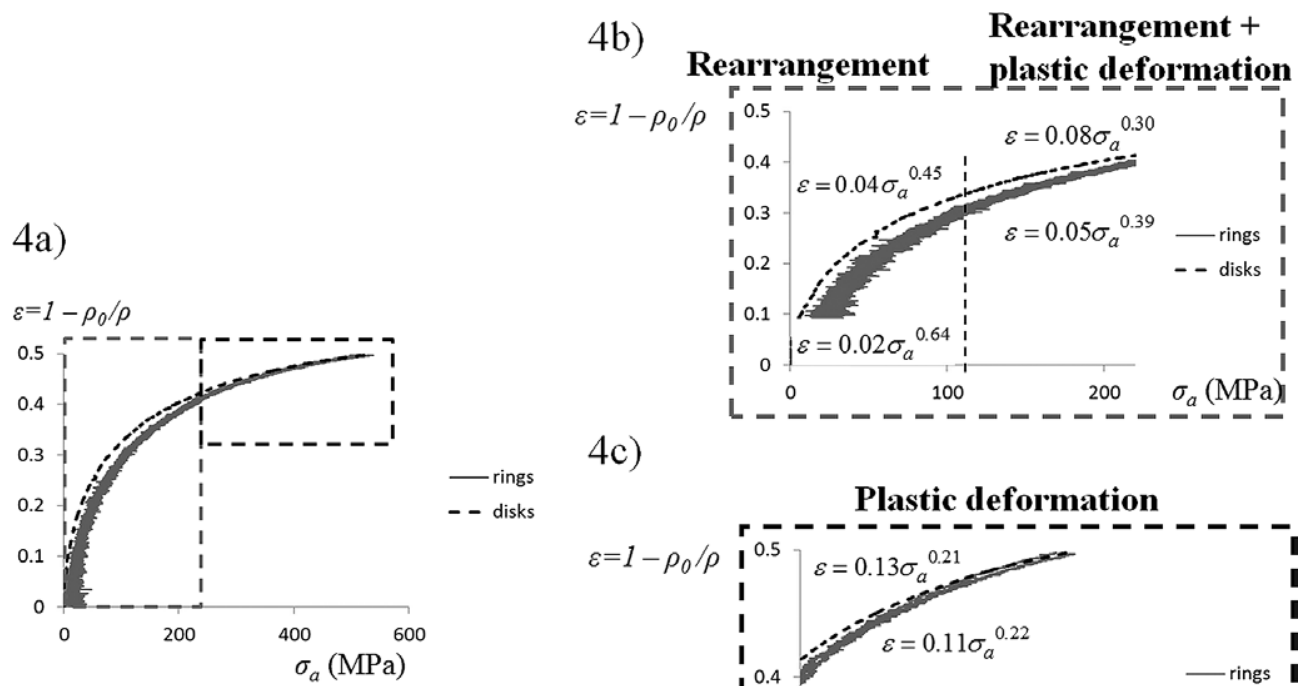

$4 c)$

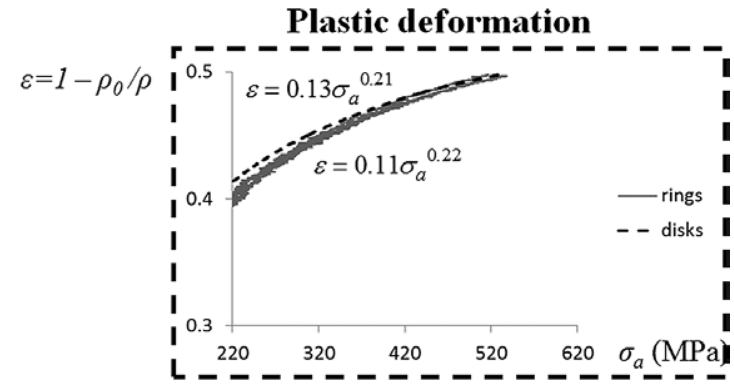

Fig. 4 Densification versus mean axial stress - whole compaction cycle (4a), beginning of compaction (4b), last stage of compaction (4c).

Fig. 4 shows densification as a function of mean axial stress, distinguishing the deformation mechanisms during compaction cycle in three corresponding intervals of mean axial stress.

In previous work a deep analysis of data and possible fitting curves has been performed, relationships best fitting the experimental data are the power law relationships expressed in general form by equation $(7)^{21,22)}$. These relationships also have physical meaning, as it will be explained in the following.

$$
\varepsilon=1-\rho_{0} / \rho=A \cdot \sigma_{a}^{B}
$$

The intervals and the equations shown in Fig. 4 are those minimising the differences between data and fitting curves. Curves are now perfectly overlapped in the final stage of compaction, where plastic deformation prevails, but still differences are observed in the first stage, where rearrangement prevails. As shown in Fig. 4, parameters $A$ and $B$ in the power law relationship change during compaction, they are reported in Fig. 5 to be directly compared.

Parameter $A$ increases during compaction, and it is slightly higher for disks, while parameter $B$ decreases during compaction and it is higher for rings. Aiming at identifying a physical meaning in the trend of $A$ and $B$ parameters, the well-known HollomonLudwik equation describing plastic (irreversible) deformation in metals, equation (8), is recalled

$$
\sigma_{t}=K \cdot \varepsilon_{t}^{n}
$$

where $\sigma_{t}$ is the true stress, $K$ the strength coefficient, $\varepsilon_{t}$ the true 


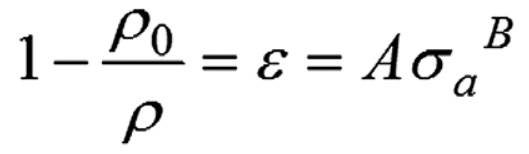

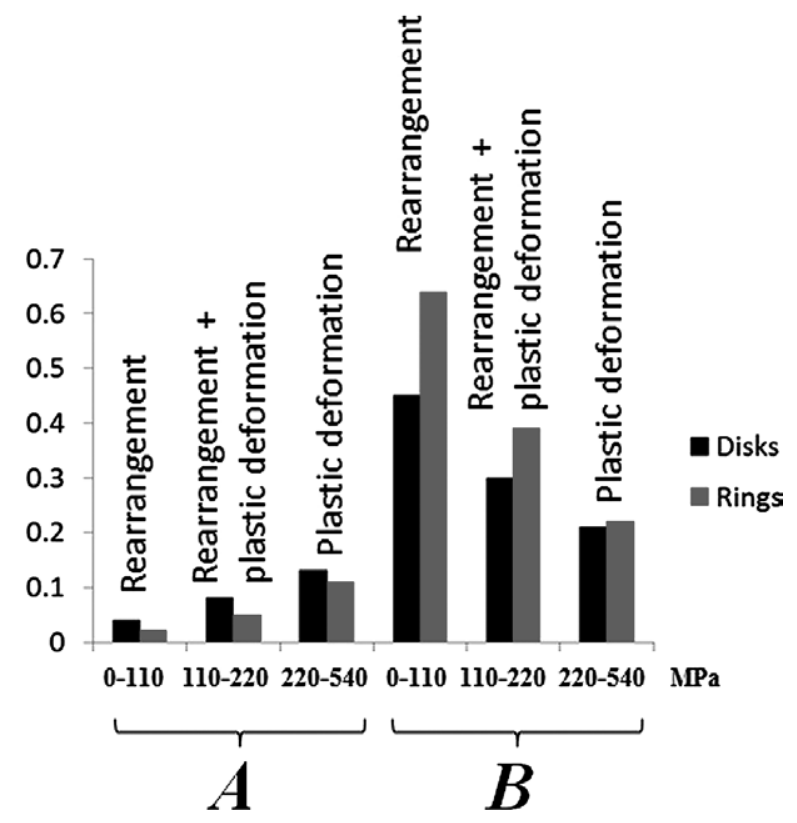

Fig. $5 A$ and $B$ parameters in the different stages of compaction.

strain, and $n$ the strain hardening coefficient. With respect to bulk metals deformation due to uniaxial stress, differences have to be highlighted when referring to deformation occurring during compaction: density is continuously increasing, so that no true stress-true strain relationships can be considered; powder mix is made by irregularly shaped powder particles, to which lubricant and graphite are added, and pores are also present; different deformation mechanisms occur, such as rearrangement, plastic deformation of powder particles, viscous deformation of lubricant; moreover, loading conditions are tri-axial, and locally may be very different from nominal ones. Nevertheless, despite all the main issues typical of powder mixes, the physical meaning of parameters in the equations fitting the deformation curve during compaction is the same as that of parameters in the Hollomon-Ludwik equation, when expressed as a strain-stress relationship as in equation (9)

$$
\varepsilon_{t}=K^{-1 / n} \cdot \sigma_{t}^{1 / n}
$$

Comparing equations (7) and (9), parameter $A$ is physically a sort of "deformation coefficient" (same as $K^{1 / n}$, inverse of the strength coefficient), and parameter $B$ a "strain softening coefficient" (same as $1 / n$, inverse of the strain hardening coefficient). According to this interpretation, the trend of $A$ and $B$ during compaction, as shown in Figs. 4 and 5, can be explained: $A$ increases during compaction, as well as the deformation of particles, while $B$ decreases because deformed particles oppose further deformation. Moreover, in the first stage of compaction, for disks $A$ is larger, due to the larger space which makes rearrangement easier, and $B$ is lower, because particles which encountered earlier rearrangement, earlier oppose to further deformation.

The analysis above allowed deriving density distribution, shown in Fig. 6 distinguishing disks and rings (6a), and grouping disks and rings with similar geometrical parameter (6b)

Fig. 6a shows that, as expected, the density gradient increases on increasing $H / D, H /\left(D_{\text {ext }}-D_{\text {int }}\right)$, and the maximum difference between mean and minimum relative density is observed in the highest rings $\left(\Delta \rho_{r}=0.03\right.$, corresponding to $\left.0.23 \mathrm{~g} / \mathrm{cm}^{3}\right)$. However, as by Fig. 6b, comparing disks and rings with similar geometrical parameters, the density gradient is exactly the same.

\section{Summary}

This work, based on the data continuously recorded by an industrial press without any additional special device, allowed highlighting the influence of geometry on densification of low alloy steel powder disks and rings characterised by different $H / D, H /\left(D_{\text {ext }}-D_{\text {int }}\right)$ ratios. Relative in situ density as a function of the compaction stress has been directly derived from the recorded data, showing a significant influence of the geometry. Single action compaction experiments allowed deriving the mean axial stress and the constitutive model of the powder mix. Relative in situ density as a function of the mean axial stress is less affected by the geometry. Densification has been expressed in terms of the deformation of the powder mix, and related to the mean axial stress by a power law equation with physical meaning. Density distribution in the axial direction has been investigated, and the same density gradient has been observed for disks and rings with similar $\mathrm{H} / \mathrm{D}, \mathrm{H} /\left(\mathrm{D}_{\mathrm{ext}}-\mathrm{D}_{\mathrm{int}}\right)$ ratios. 6a)

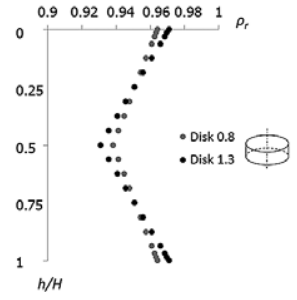

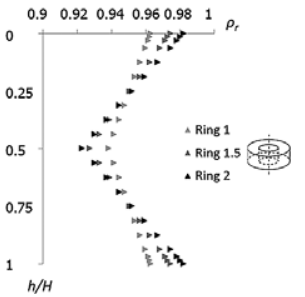

6b)
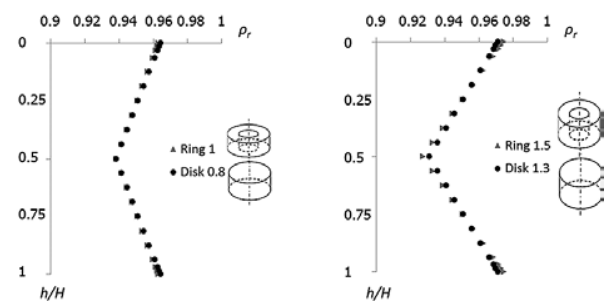

Fig. 6 Density gradient distinguishing disks and rings (6a) and grouping disks and rings with same geometrical parameter (6b). 


\section{References}

1) L. Parilak, E. Dudrova, R. Bidulsky, M. Kabatova: Powder Technology, 332 (2017) 447-460.

2) P. J. Denny: Powder Technology, 127 (2002) 162-172.

3) J. M. Montes, F. G. Cuevas, J. Cintas, Y. Torres: Granular Matter, 12 (2010) 617-627.

4) R. Panelli, F. A. Filho: Powder Metallurgy, 41 (1998) 131133.

5) Ge Rong-de: International Journal of Powder Metallurgy, 27 (1991) 211-216.

6) A. Secondi: Powder Metallurgy, 45 (2002) 213-217.

7) G. Aryanpour, M. Farzaneh: Powder Technology, 277 (2015) 120-125.

8) A. Molinari, I. Cristofolini, G. Pederzini, A. Rambelli: The International Journal of Powder Metallurgy, 53 (2017) 41-48

9) M. A. E. Saleh, S. Shima: J. Jpn. Soc. Powder Powder Metallurgy, 41 (1994) 1541-1546.

10) T. Itoh, Y. Wanibe: J. Jpn. Soc. Powder Powder Metallurgy, 46 (1999) 16-21.

11) I. Cristofolini, A. Rambelli, G. Pederzini, A. Molinari: Powder Metallurgy, 59 (2016) 73-84.

12) H. He, T. J. Evans, A. B. Yu, R. Y. Yang: Powder Technology, 319 (2017)183-190.
13) B. Wikmann, N. Solimannezhad, R. Larsson, M. Olderburg, H. A. Haggblad: Powder Metallurgy, 43 (2000) 132-138.

14) E. Pavier, P. Doremus: Powder Metallurgy, 42 (1999) 345-352.

15) I. Cristofolini, A. Molinari, G. Pederzini, M. Piva, A. Grandi: Advances in powder Metallurgy and Powder Technology, 1 (2015) 19-30.

16) I. Cristofolini, A. Rambelli, G. Pederzini, A. Molinari: Powder Technology, 295 (2016) 284-295.

17) I. Cristofolini, A. Molinari, G. Pederzini, A. Rambelli: Advances in Powder Metallurgy \& Particulate Materials, 1 (2016) $34-44$.

18) A. Molinari, I. Cristofolini, G. Pederzini, A. Rambelli: The International Journal of Powder Metallurgy, 53 (2017) 41-48.

19) I. Cristofolini, A. Molinari, M. Zago, G. Pederzini, A. Rambelli: Advances in Powder Metallurgy \& Particulate Materials, 1 (2017) 30-40.

20) I. Cristofolini, G. Pederzini, A. Rambelli, A. Molinari: Proceedings WorldPM2016 - Powder Pressing (2016).

21) I. Cristofolini, A. Molinari, G. Pederzini, A. Rambelli: Powder Metallurgy, 61 (2018) 10-20

22) I. Cristofolini, G. Pederzini, A. Rambelli, A. Molinari, “A pressure/deformation analysis of the compressibility of low alloy iron powder mixes": submitted to Powder Technology 